\title{
Novel UV Sensing and Photocatalytic Properties of $\mathrm{DyCoO}_{3}$
}

\author{
Carlos R. Michel $\mathbb{D}^{1},{ }^{1}$ Miguel A. Lopez-Alvarez $\mathbb{D}$, ${ }^{1}$ \\ Alma H. Martínez-Preciado $\mathbb{D}^{2},{ }^{2}$ and Gregorio G. Carbajal-Arízaga $\mathbb{B}^{3}$ \\ ${ }^{1}$ Departamento de Física, Universidad de Guadalajara CUCEI, Guadalajara, Jalisco 44430, Mexico \\ ${ }^{2}$ Departamento de Ingeniería Química, Universidad de Guadalajara CUCEI, Guadalajara, Jalisco 44430, Mexico \\ ${ }^{3}$ Departamento de Química, Universidad de Guadalajara CUCEI, Guadalajara, Jalisco 44430, Mexico \\ Correspondence should be addressed to Carlos R. Michel; michelucr@yahoo.es
}

Received 31 January 2019; Revised 14 May 2019; Accepted 21 May 2019; Published 9 June 2019

Academic Editor: Sang Sub Kim

Copyright (C) 2019 Carlos R. Michel et al. This is an open access article distributed under the Creative Commons Attribution License, which permits unrestricted use, distribution, and reproduction in any medium, provided the original work is properly cited.

\begin{abstract}
Oxides with the perovskite type structure of formula $\mathrm{LnCoO}_{3}$, where $\mathrm{Ln}$ is a rare earth element, have unique physical and chemical properties. These materials are applied in catalysis, gas sensors, and electrodes for solid oxide fuel cells, among others. In this work, single-phase $\mathrm{DyCoO}_{3}$ was obtained at $900^{\circ} \mathrm{C}$ using the solution-polymerization method. The microstructure of this material corresponds to a dendritic-type shape, with grain size between 0.2 and $8 \mu \mathrm{m}$ and abundant porosity. The ultraviolet (UV) sensing characterization was performed on sintered pellets made with the as-prepared $\mathrm{DyCoO}_{3}$ powder. The UV source was a light emitting diode (LED) of wavelength $(\lambda)$ of $365 \mathrm{~nm}$. The detection of this radiation, with constant optical irradiance $\left(\mathrm{E}_{\mathrm{e}}\right)$, produced uniform and reproducible response patterns. When $\mathrm{E}_{\mathrm{e}}$ was increased, the graphs revealed a quantitative detection of the light. Analogous results were obtained using light of larger wavelengths: $\lambda=400,449$, and $642 \mathrm{~nm}$. The graphs display a decrease on the variation of the photocurrent by increasing $\lambda$, corresponding to a decrease on the energy of the incoming photons. On the other hand, the photocatalytic decomposition of malachite green under UV radiation was investigated using powder of $\mathrm{DyCoO}_{3}$. The results show a decrease of the absorbance by increasing the UV exposure time, indicating the degradation of the dye. Since $\mathrm{DyCoO}_{3}$ is a p-type semiconductor material, the generation of electrical charge carriers under UV radiation explains its photocurrent and photocatalytic properties. In general, these properties can be applied in UV sensors to prevent skin cancer, photoconductive materials for solar photocells, and photocatalysis to decompose organic dyes.
\end{abstract}

\section{Introduction}

In recent years, cobalt-based perovskites of formula $\mathrm{LnCoO}_{3}$, where $\mathrm{Ln}$ is a rare earth element, have attracted considerable interest due to their outstanding physical and chemical properties. These properties have found application in different areas like heterogeneous catalysis, solid oxide fuel cells, thermoelectricity, gas sensors, and photocatalysis, among others [1-11]. About their magnetic and electrical properties, a lot of experimental and theoretical researches have been done; however, the interpretation of the results is still under debate [12]. Different types of magnetic ordering have been identified in these materials, which depends on the Ln cation and the $\mathrm{Co}^{3+}$ spin state $[13,14]$. In $\mathrm{LaCoO}_{3}$, three electron spin states for cobalt have been detected: low spin $\left(t_{2} g^{6} e_{g}{ }^{0}\right)$, intermediate-spin $\left(\mathrm{t}_{2} \mathrm{~g}^{5} \mathrm{e}_{\mathrm{g}}{ }^{1}\right)$, and high-spin $\left(\mathrm{t}_{2} \mathrm{~g}^{4} \mathrm{e}_{\mathrm{g}}{ }^{2}\right)[15]$.
Besides, from electrical measurements, an insulator to metal transition has been observed at around $600 \mathrm{~K}$, which is associated to changes in the spin configuration. Even though the physical and chemical properties of $\mathrm{LaCoO}_{3}$ have been studied extensively, significantly less information is available for cobalt perovskites containing other rare earth elements.

In this work the detection of ultraviolet radiation (UV) using $\mathrm{DyCoO}_{3}$ was investigated. Even though UV represents a small region of the electromagnetic spectrum, from 100 to $400 \mathrm{~nm}$, its effect on human beings is of particular concern, because it causes skin cancer and eye damage $[16,17]$. Other harmful effects occur in plants, where the photosynthesis can be significantly affected by an overexposure to UV light [18]. Therefore, the development of materials able to detect UV radiation is worth investigation. The photodetection properties of perovskite oxides have been previously investigated; 
however, they have been limited to few compounds like $\mathrm{BaTiO}_{3}, \mathrm{SrTiO}_{3}, \mathrm{LiNbO}_{3}$, and $\mathrm{LiTaO}_{3}$ [19-22]. In the case of cobalt-based perovskites, Liu et al. studied the detection of visible light using nanostructured $\mathrm{LaCoO}_{3}$ thin films, grown epitaxially on $\mathrm{SrTiO}_{3}$ substrates [23]. They reported that photoconduction depends on the crystallographic orientation of the films. However, for $\mathrm{DyCoO}_{3}$, the detection of UV and light in the visible region has not been reported yet, in our knowledge.

On the other hand, the photocatalytic decomposition of toxic compounds by means of metal oxides has received a great deal of attention throughout the world. This process seeks to mitigate the harmful effects of these chemicals in the environment, once they have been used in the fabrication of a number of products. Even though the most studied photocatalyst is $\mathrm{TiO}_{2}$, notable results have been obtained from $\mathrm{GdCoO}_{3}$ and $\mathrm{LaCoO}_{3}[9-11,24]$. The rare earth element in these compounds plays a key role in the photocatalytic activity because of their partly occupied $4 \mathrm{f}$ levels. Besides, cobalt is catalytically active due to its mixed-valence state and electrical properties. Therefore, the photocatalytic degradation of a typical dye (malachite green) under UV light using powder of $\mathrm{DyCoO}_{3}$ was investigated in this work.

\section{Materials and Methods}

$\mathrm{DyCoO}_{3}$ was synthesized by the solution-polymerization method, using stoichiometric amounts of $\mathrm{Dy}\left(\mathrm{NO}_{3}\right)_{3} \cdot 6 \mathrm{H}_{2} \mathrm{O}$ (99.9\%, Sigma) and $\mathrm{Co}\left(\mathrm{NO}_{3}\right)_{2} \cdot 6 \mathrm{H}_{2} \mathrm{O}(99 \%$, J.T. Baker). The latter were dissolved in $10 \mathrm{ml}$ of an aqueous solution containing $2 \mathrm{wt} \%$ of polyvinyl alcohol (Aldrich), which acted as polymerizing agent. After stirring for $24 \mathrm{~h}$, the solvent was evaporated by microwave irradiation, using a home microwave oven. An exothermic reaction took place at the end of the evaporation, which was observed by a brief ignition of the dried material. The resulting precursor was calcined from 700 to $900^{\circ} \mathrm{C}$ in air, for $5 \mathrm{~h}$, using a muffle-type furnace.

The crystal structure of calcined powders was characterized by X-ray powder diffraction (XRD), at room temperature, using an Empyrean (PANalytical) diffractometer $(\mathrm{Cu}$ $\mathrm{K}_{\alpha 1}$ radiation). The microstructure of samples was observed by field emission scanning electron microscopy (FESEM), using a Tescan (Mira) microscope. Surface chemical analysis was done by using a Brucker X-ray energy dispersive spectrometer, attached to the FESEM. Surface characterization was also performed by X-ray photoelectron spectroscopy (XPS), using a Thermo Scientific K-Alpha spectrometer, which has a monochromatic $\mathrm{Al} \mathrm{K}_{\alpha}$ source $(1486 \mathrm{eV})$.

Photocurrent measurements were carried out on sintered $\mathrm{DyCoO}_{3}$ pellets prepared by pressing $500 \mathrm{mg}$ of the powder at $120 \mathrm{~kg} / \mathrm{cm}^{2}$, followed by calcination at $700^{\circ} \mathrm{C}$ for $5 \mathrm{~h}$. These pellets had $1 \mathrm{~cm}$ diameter and $2 \mathrm{~mm}$ thickness. Two high purity silver wires (99.99\%, Aldrich) were attached to each pellet, which acted as electrical contacts. Electrical current measurements were done in direct current mode (DC) using a digital voltmeter (Agilent 34401A). The UV source was a light emitting diode (LED) of $\lambda=365 \mathrm{~nm}$, with variable optical irradiance $\left(\mathrm{E}_{\mathrm{e}}\right)$ of up to $200 \mathrm{~mW} / \mathrm{cm}^{2}$. LEDs of $\lambda=$

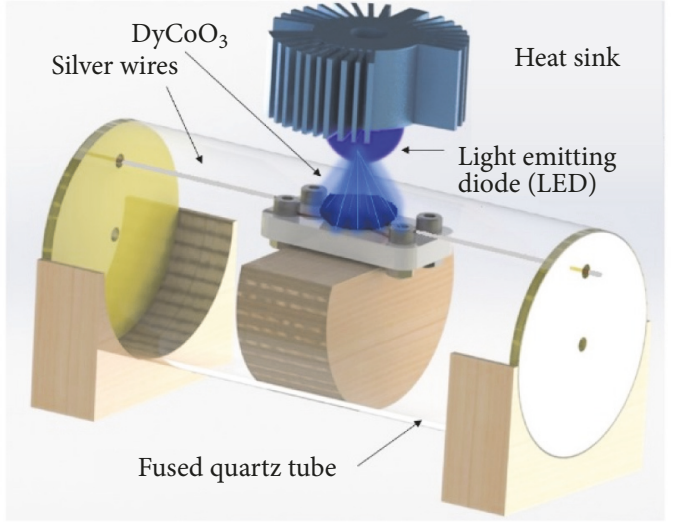

FIGURE 1: Drawing of the experimental setup used for the photocurrent measurements.

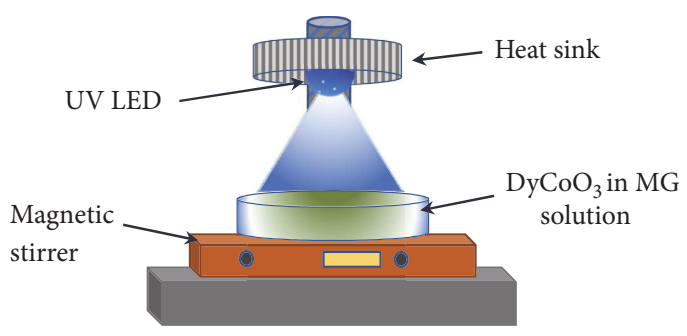

FIgURE 2: Scheme of the UV light photocatalytic reactor.

400 (violet), 449 (blue), and 642 (red) nm were also used. To avoid contamination of the pellet, it was placed inside a fused quartz tube with sealed plastic lids at both ends; Figure 1 shows a drawing of the experimental setup. The radiation emitted by the LEDs was measured by means of a Thorlabs optical power meter (PM 100D). This instrument has a $\mathrm{Si}$ photodiode (model S120VC) for detecting radiation in the range $200-1100 \mathrm{~nm}$.

The photocatalytic degradation of malachite green (MG) was evaluated in a home-made photoreactor, using UV LED with $\mathrm{E}_{\mathrm{e}}=100 \mathrm{~mW} / \mathrm{cm}^{2}$. For this purpose, 10 and $20 \mathrm{mg}$ of $\mathrm{DyCoO}_{3}$ in powder were used as photocatalysts. The powders were dispersed in $40 \mathrm{ml}$ of a MG aqueous solution, with concentration of $1.6 \times 10^{-5} \mathrm{M}$ and $\mathrm{pH}=4.7$. Figure 2 shows a scheme of the experimental setup used in the photocatalysis tests. The heat sink shown in this picture was used to dissipate the heat produced by the LED. Samples were collected at different periods of time and characterized by UV-vis spectrophotometry (Thermo Scientific, Helios Zeta). FTIR analyses of $\mathrm{DyCoO}_{3}$ samples (before and after the photocatalysis) were performed with a Thermo Scientific Nicolet iS5 spectrometer.

The efficiency of the photocatalytic degradation of MG by $\mathrm{DyCoO}_{3}$ was determined by using Eq. No. (1):

$$
\% \text { Degradation }=\frac{C_{o}-C}{C_{o}} \times 100 \%=\frac{A_{o}-A}{A_{o}} \times 100 \%
$$

where $C_{0}$ is the concentration of the original MG solution and $C$ corresponds to the concentration after its irradiation. 


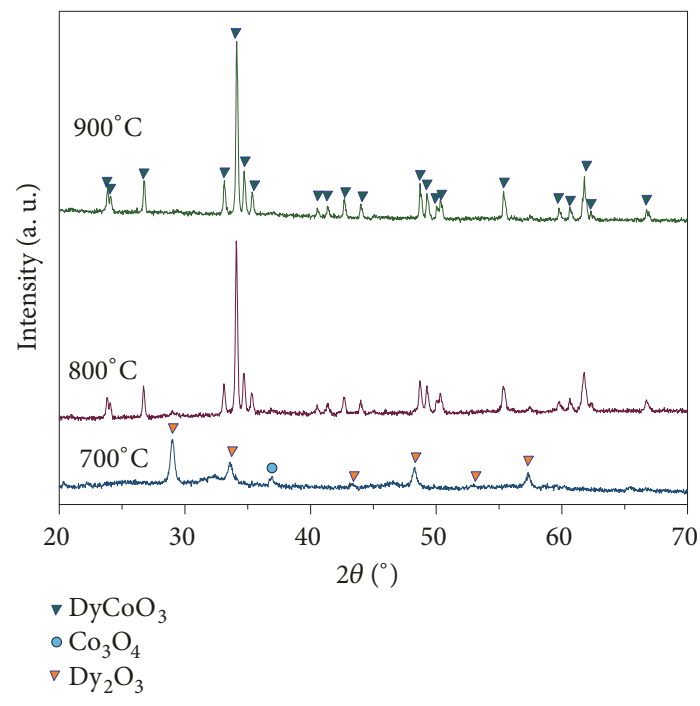

FIGURE 3: X-ray diffraction patterns of materials calcined from 700 to $900^{\circ} \mathrm{C}$, in air.

Similarly, $A_{0}$ and $A$ are the absorbance values of the solution, before and after its degradation.

\section{Results and Discussion}

3.1. Crystal Structure, Morphology, and Surface Chemical Composition of $\mathrm{DyCoO}_{3}$. Figure 3 shows XRD patterns obtained from powders calcined at 700,800 , and $900^{\circ} \mathrm{C}$. The pattern of the material annealed at $700^{\circ} \mathrm{C}$ shows the main diffraction lines of $\mathrm{Dy}_{2} \mathrm{O}_{3}$ and $\mathrm{Co}_{3} \mathrm{O}_{4}$, which were identified by means of the JCPDF files Nos. 43-1006 and 09-0418, respectively. The calcination at $800^{\circ} \mathrm{C}$ yielded $\mathrm{DyCoO}_{3}$, as result of the reaction between $\mathrm{Dy}_{2} \mathrm{O}_{3}$ and $\mathrm{Co}_{3} \mathrm{O}_{4} \cdot \mathrm{DyCoO}_{3}$ was identified by using the JCPDF file No. 25-1051. An improvement of the crystallinity and the near absence of XRD lines of $\mathrm{Dy}_{2} \mathrm{O}_{3}\left(2 \theta=28.9^{\circ}\right.$ and $\left.57.5^{\circ}\right)$ and $\mathrm{Co}_{3} \mathrm{O}_{4}\left(2 \theta=37^{\circ}\right)$ were observed from a sample calcined at $900^{\circ} \mathrm{C}$.

The XRD results obtained in this work were compared with those published for $\mathrm{DyCoO}_{3}$ prepared by the citrate, drip pyrolysis, and microwave-assisted methods [25-27]. By the citrate method, $\mathrm{DyCoO}_{3}$ was obtained from the calcination of a precursor material at $950^{\circ} \mathrm{C}$, for $12 \mathrm{~h}$, whereas by drip pyrolysis the synthesis required the annealing of pellets pressed at $3 \mathrm{ton} / \mathrm{cm}^{2}$, at $1000^{\circ} \mathrm{C}$, for $24 \mathrm{~h}$. By the microwave-assisted method a reaction temperature was not reported, but according to the authors it was far above $700^{\circ} \mathrm{C}$. A full match among our results and those reported in the literature was observed.

The microstructure of $\mathrm{DyCoO}_{3}$ calcined at $900^{\circ} \mathrm{C}$ was observed by FESEM; Figures 4(a) and 4(b) display two typical images acquired at different magnifications. The morphology can be described as particles of dendritic-type shape surrounded by abundant porosity; the grain size was in the range $0.2-8 \mu \mathrm{m}$. Nanostructured oxides can be synthesized by the solution-polymerization method; however, the annealing temperature needed to produce $\mathrm{DyCoO}_{3}$ yielded in this work a micron-sized material. Since the morphology of $\mathrm{DyCoO}_{3}$ synthesized by the methods previously cited was not reported, it was not possible to perform a comparison of the microstructure of our samples. Figure 4(c) displays an EDS spectrum of $\mathrm{DyCoO}_{3}$; this graph shows the main peaks of dysprosium, located at 1.3, 6.5, and $7.2 \mathrm{keV}$; cobalt, at $0.75,6.9$, and $7.6 \mathrm{keV}$; oxygen, at $0.5 \mathrm{eV}$. The peak observed at $2.12 \mathrm{keV}$ is associated to the $\mathrm{M}$ orbital of gold, which was deposited on $\mathrm{DyCoO}_{3}$ as a thin film, prior to the observation by FESEM. In general, the EDS analysis confirmed the formation of $\mathrm{DyCoO}_{3}$. Figure 4(d) shows the microstructure of a $\mathrm{DyCoO}_{3}$ pellet, sintered at $700^{\circ} \mathrm{C}$, prepared with the as-synthesized powder. This image reveals the formation of a denser solid, with better connectivity among grains, which was intended to facilitate the transport of charge carriers during the electrical characterization.

Figure 5(a) displays a wide XPS scan of $\mathrm{DyCoO}_{3}$ showing the presence of carbon, dysprosium, cobalt, and oxygen, whose peaks correspond to that reported in the literature [28]. The carbon 1s peak is associated to the adhesive used to fix the sample for XPS analysis. Figure 5(b) shows a narrow scan of Dy $3 d_{3 / 2}$ and $3 d_{5 / 2}$ levels, whereas the $4 d$ peak of this element, located at approximately $152.4 \mathrm{eV}$, is shown in the inset of this figure. The latter can be deconvoluted into two peaks, corresponding to Dy $4 \mathrm{~d}_{5 / 2}$ and $4 \mathrm{~d}_{3 / 2}$, which indicates the oxidation state $3+$ for Dy [29]. Figure 5(c) displays the cobalt $2 \mathrm{p}_{1 / 2}$ and $2 \mathrm{p}_{3 / 2}$ levels, which are detected through the peaks located at approximately 795 and $780 \mathrm{eV}$, respectively. These peaks were deconvoluted as shown in the same graph. The interpretation of them indicates that the peaks centered at 780.17 and $794.15 \mathrm{eV}$ are attributed to $\mathrm{Co}^{3+}$, whereas the peaks at 781.7 and $797.1 \mathrm{eV}$ are related to $\mathrm{Co}^{2+}$. Moreover, the area associated to each oxidation state of cobalt was determined, resulting in $54.6 \%$ for $\mathrm{Co}^{3+}$ and $45.4 \%$ for $\mathrm{Co}^{2+}$. Figure $5(\mathrm{~d})$ shows a narrow scan around the oxygen 1s level, from which the deconvolution reveals three peaks centered at 529.2, 530.7, and $532.4 \mathrm{eV}$. The first two are associated to $\mathrm{O} 1 \mathrm{~s}(\mathrm{Co}-\mathrm{O}$ and Dy-O bonds) and $\mathrm{OH}^{-}$, respectively. The small peak located at $532.4 \mathrm{eV}$ can be attributed to a C-O bond, caused by a slight carbonation of the sample, due to the fact that the synthesis was performed in atmospheric conditions.

\subsection{Photocurrent Properties of $\mathrm{DyCoO}$}

3.2.1. Detection of UV Light. The most studied materials for detecting UV radiation are wide-bandgap semiconductors like $\mathrm{SnO}_{2}, \mathrm{Nb}_{2} \mathrm{O}_{5}, \mathrm{TiO}_{2}, \mathrm{ZnO}$, and $\mathrm{ZnS}$, among others, which have been applied in photoconductive cells from time ago [30-32]. A key parameter to be considered for this application is the bandgap energy; that for these materials is in the range 3.2 to $4.9 \mathrm{eV}$. Regarding $\mathrm{DyCoO}_{3}$, the electrical, magnetic, and thermoelectric properties have been previously reported; however, its response to UV radiation has not been published $[27,33]$. Then, in this work the bandgap energy of $\mathrm{DyCoO}_{3}$ was estimated through UV-Vis spectroscopy using Tauc plots $\left((\alpha h \nu)^{\mathrm{n}} v s . h \nu\right)$, where $\alpha$ is the optical absorption coefficient, $h$ is the Planck constant, and $v$ is the frequency of the light; the term $h v$ represents the photon energy. Figure 6 shows 


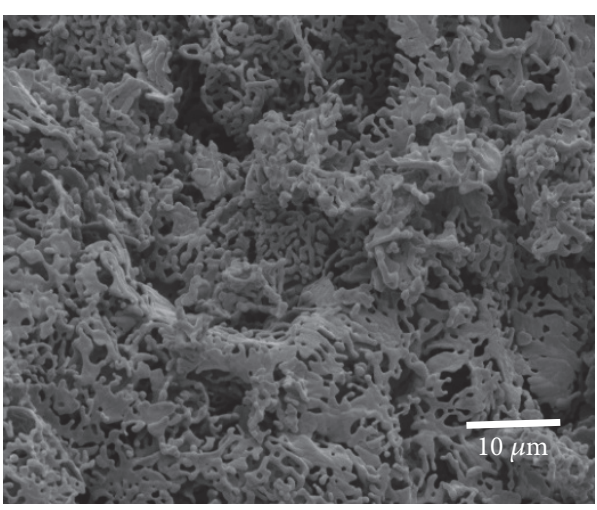

(a)

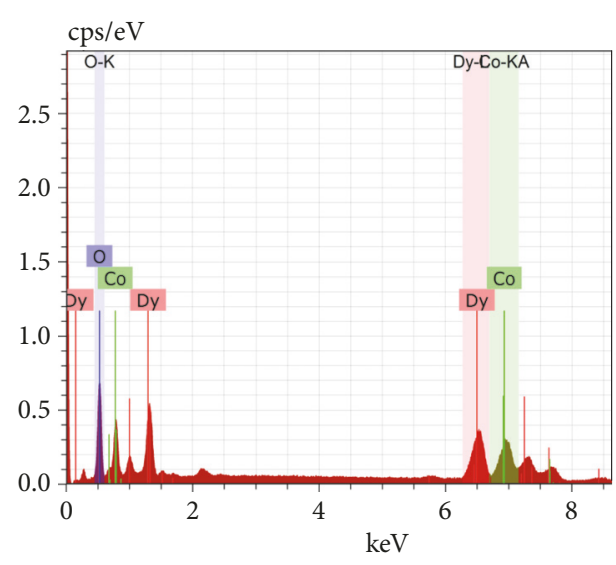

(c)

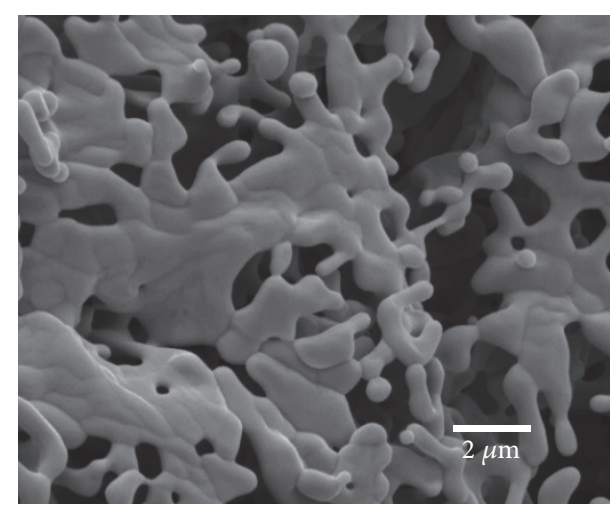

(b)

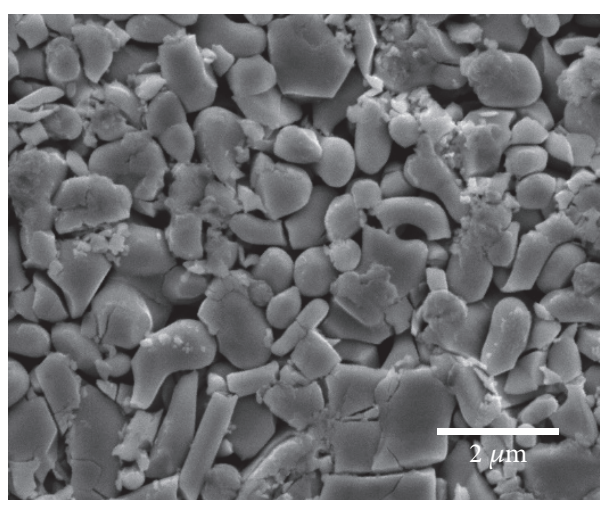

(d)

Figure 4: Surface morphology ((a) and (b)) of $\mathrm{DyCoO}_{3}$ calcined at $900^{\circ} \mathrm{C}$; (c) corresponding EDS analysis; (d) microstructure of a DyCoO 3 pellet sintered at $700^{\circ} \mathrm{C}$.

a typical $(\alpha h \nu)^{0.5} v s$. $h v$ graph obtained from powder of $\mathrm{DyCoO}_{3}$. The intersection of the dotted line with the $\mathrm{x}$-axis indicates a bandgap energy of approximately $4.25 \mathrm{eV}$. Then, this value suggests the possible application of $\mathrm{DyCoO}_{3}$ as a UV sensor material.

In order to evaluate the photocurrent properties of $\mathrm{DyCoO}_{3}$, the variation of the electrical current (I) through a $\mathrm{DyCoO}_{3}$ pellet caused by UV radiation was measured. The applied voltage used in these measurements was $5 \mathrm{~V}$. Figures 7(a) and 7(b) show I vs. time graphs recorded when the pellet was alternatively exposed to $\mathrm{UV}\left(\mathrm{E}_{\mathrm{e}}=100 \mathrm{~mW} / \mathrm{cm}^{2}\right)$ and darkness, in periods of time of $2 \mathrm{~min}$ and $30 \mathrm{~s}$, respectively. These graphs show uniform response patterns, characterized by an increase of $I$ under UV light. The process was reversible and the magnitude of the variation of $I$ (called hereafter $\Delta I$ ) depends on the UV exposure time. For instance, when the film was exposed for $2 \mathrm{~min}$, the average $\Delta I$ was $0.12 \mathrm{~mA}$, whereas, in periods of $30 \mathrm{~s}, \Delta I$ was $0.06 \mathrm{~mA}$. $\Delta I$ also depends on the optical irradiance $\left(\mathrm{E}_{\mathrm{e}}\right)$ of the incoming UV light, and Figure 7 (c) displays a typical $I$ vs $t$ plot obtained when $\mathrm{E}_{\mathrm{e}}$ increased steadily from 20 to $90 \mathrm{~mW} / \mathrm{cm}^{2}$, with $2 \mathrm{~min}$ of exposure to each $\mathrm{E}_{\mathrm{e}}$ value. In this case, $\Delta I$ increased from 0.027 to $0.1 \mathrm{~mA}$, approximately. Figure 7 (c) also displays that regardless of $\mathrm{E}_{\mathrm{e}}$ when the $\mathrm{UV}$ source was turned off the current returned to its original value. Moreover, a quasilinear relationship between $\Delta I$ and $\mathrm{E}_{\mathrm{e}}$ was deducted, as shown in Figure $7(\mathrm{~d})$. It is important to mention that the different values of $\mathrm{E}_{\mathrm{e}}$ were obtained by supplying specific voltages to the LED by means of a variable DC power supply.

Figure 8 shows polarization curves ( $I-\mathrm{V}$ plots) obtained in darkness and UV light with $\mathrm{E}_{\mathrm{e}}$ from 150 to $180 \mathrm{~mW} / \mathrm{cm}^{2}$. A nonlinear behavior of $I$ with voltage is observed in each curve, where an increase of current with $\mathrm{E}_{\mathrm{e}}$ can also be noticed. The latter agrees with the current values shown in Figure 7 (c). Moreover, in absence of light, a current of approximately $0.31 \mathrm{~mA}$ at $5 \mathrm{~V}$ was registered, which approximately matches with the current value registered in $I$ vs. time graphs of Figure $7(I=0.38 \mathrm{~mA})$. The latter suggests that the applied voltage plays a key role in the transport of charge carriers, by providing enough energy to produce their mobility. This also occurs for radiation of lower energy, as it is going to be shown later. Then, a possible mechanism to explain the detection of UV light by $\mathrm{DyCoO}_{3}$ is based on the formation of electronhole pairs on its surface, caused by the incoming photons of energy $h \nu$. The pairs are formed according to Eq. No. (2):

$$
h v \longrightarrow h^{+}+e^{-}
$$




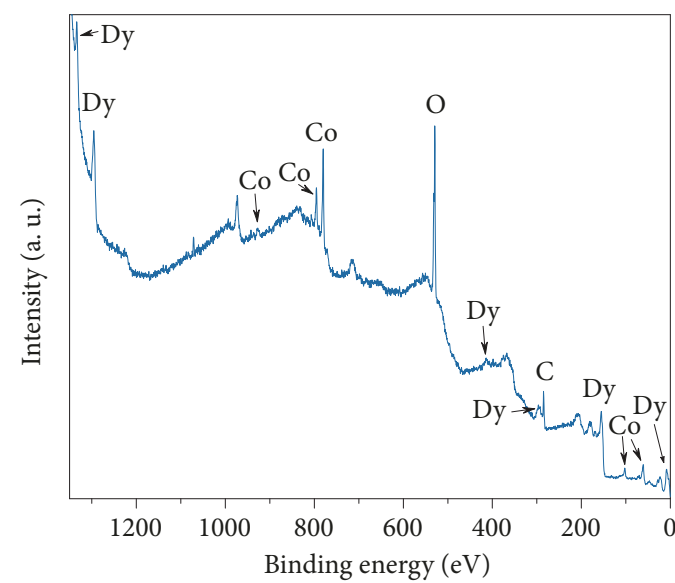

(a)

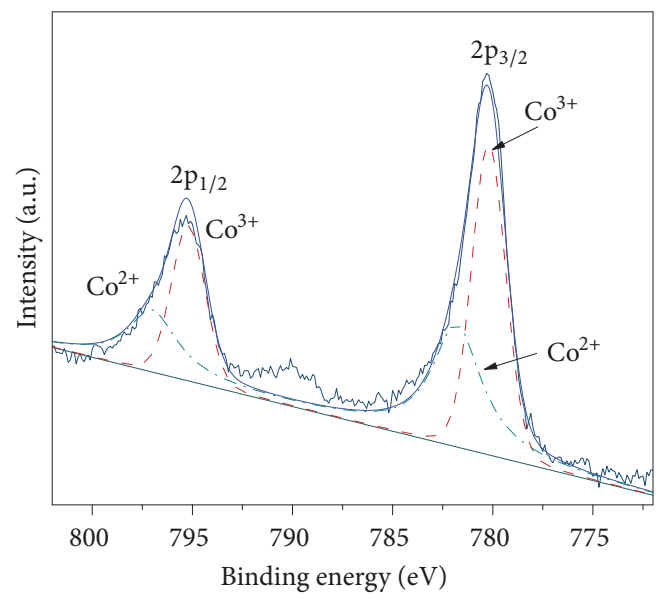

(c)

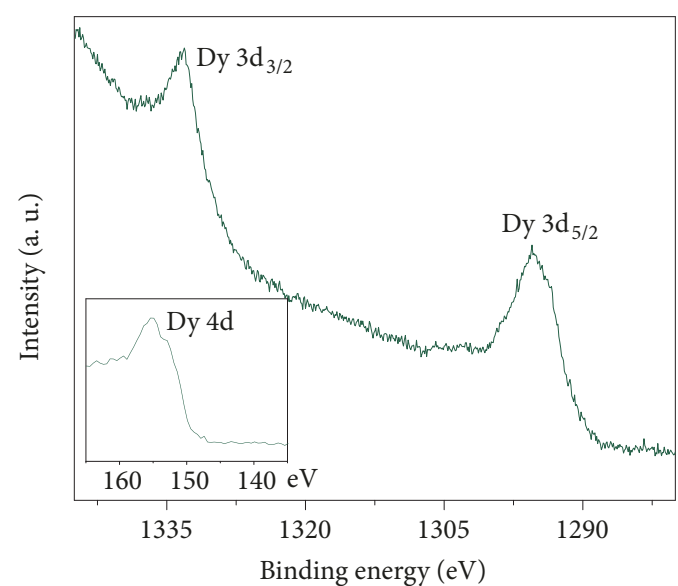

(b)

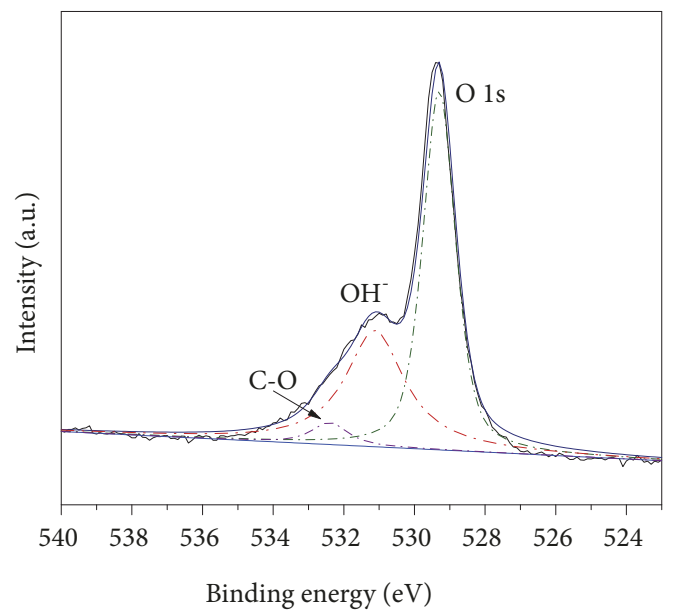

(d)

Figure 5: (a) Wide XPS scan of $\mathrm{DyCoO}_{3}$. Narrow XPS profiles of (b) Dy, (c) Co, and (d) O.

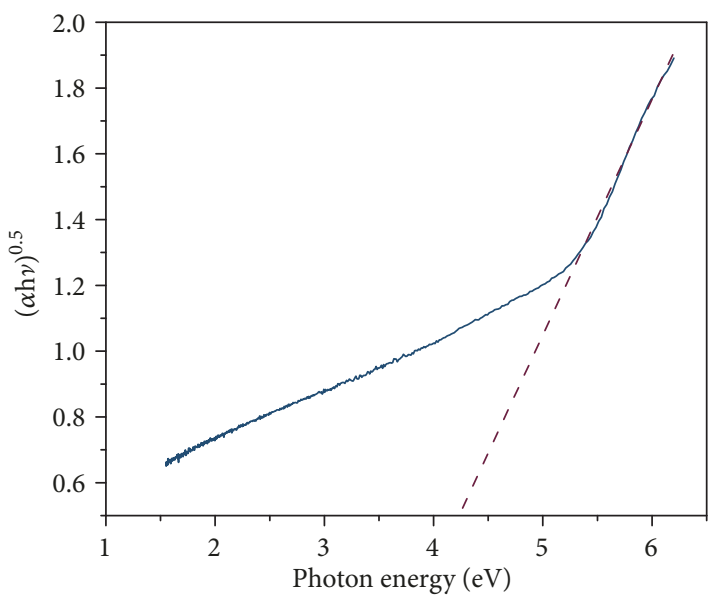

Figure 6: Determination of the bandgap energy of $\mathrm{DyCoO}_{3}$.

In a less extent, UV radiation can promote physicochemical reactions, like adsorption of oxygen molecules, which modify the electrical properties of the material. The latter can be written through Eqs. Nos. (3)-(5):

$$
\begin{gathered}
\mathrm{O}_{2}(\text { gas })+e^{-} \longrightarrow \mathrm{O}_{2}^{-}(\text {ads }) \\
\mathrm{O}_{2}(\text { gas })+4 e^{-} \longrightarrow 2 \mathrm{O}^{2-}(\text { ads }) \\
\mathrm{O}_{2}(\text { gas })+2 e^{-} \longrightarrow \mathrm{O}_{2}^{2-}(\text { ads })
\end{gathered}
$$

Since $\mathrm{DyCoO}_{3}$ is a p-type semiconductor material the depletion of electrons in its conduction band, produced by the adsorption of oxygen, increases the number of charge carriers (valence band holes). This can produce an additional increase of the electrical current. Besides, when UV light is turned off, the desorption of oxygen species takes place, decreasing $I$.

3.2.2. Responsivity of $\mathrm{DyCoO}_{3}$ in UV Light. An important parameter for UV photodetectors is the responsivity $\left(\mathrm{R}_{\mathrm{s}}\right)$, which represents the change on the electrical current in 


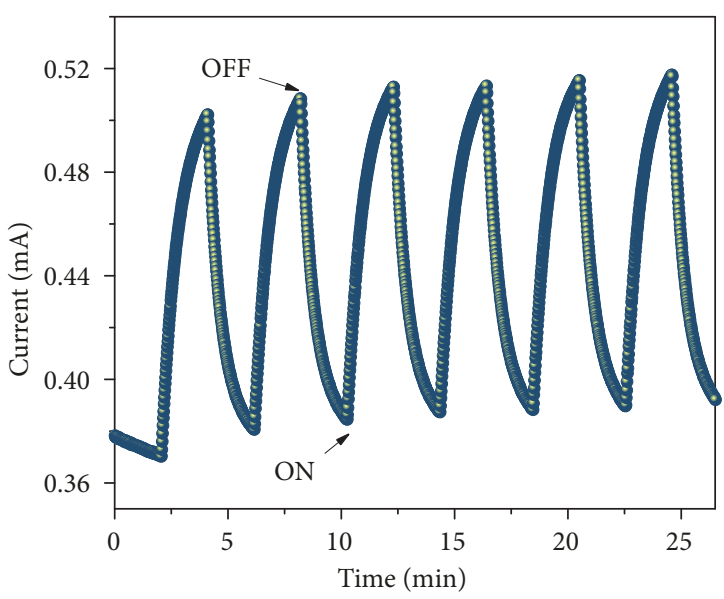

(a)

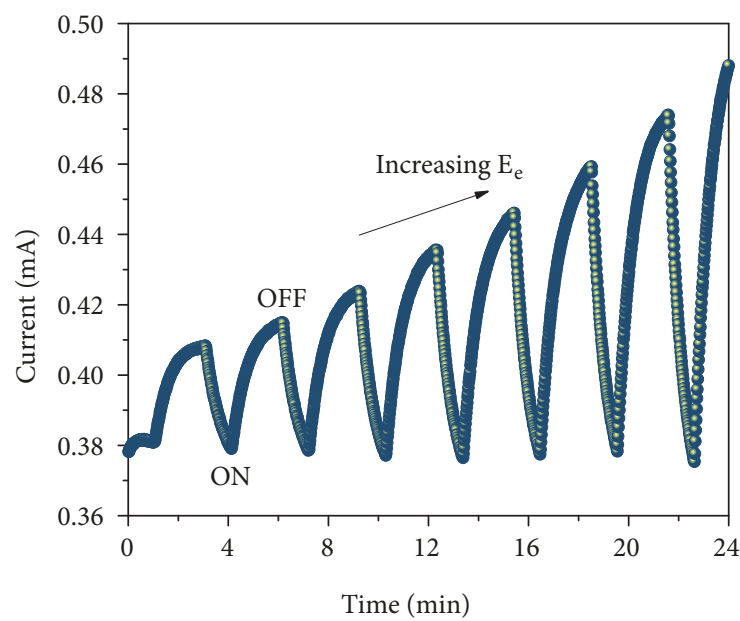

(c)

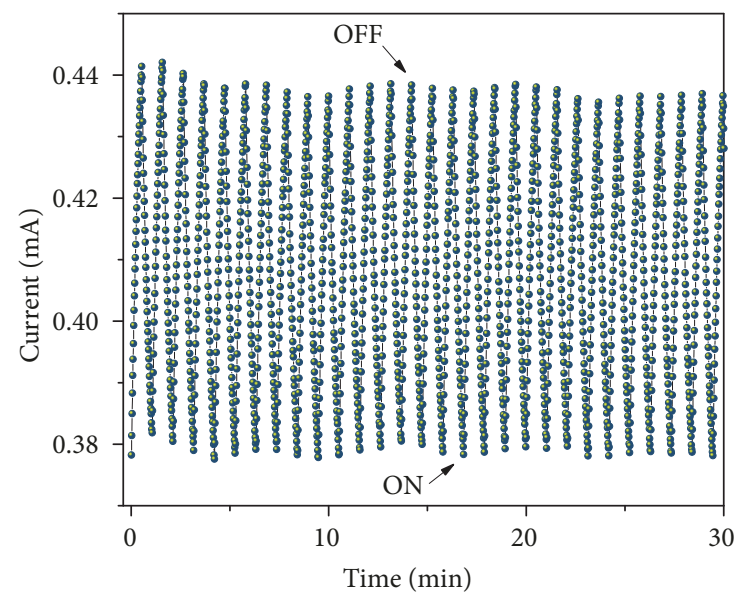

(b)

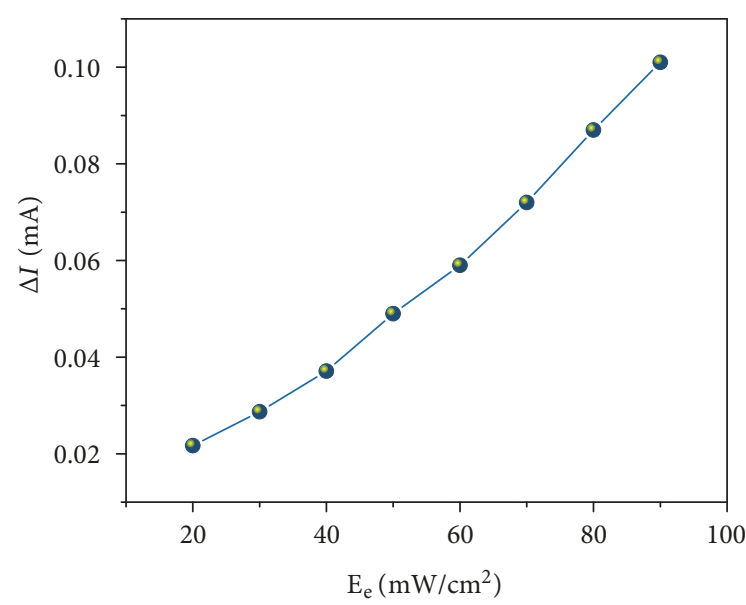

(d)

FIGURE 7: Variation of electrical current through a $\mathrm{DyCoO}_{3}$ pellet in on/off cycles of UV light of (a) 2 min and (b) $30 \mathrm{~s}$. (c) Quantitative response to UV light of several $\mathrm{E}_{\mathrm{e}}$ values. (d) Quasilinear relationship between $\Delta I$ and $\mathrm{E}_{\mathrm{e}}$.

response to a specific radiation. The responsivity of $\mathrm{DyCoO}_{3}$ was calculated by using Eq. No. (6):

$$
R_{s}=\frac{I_{p h}}{\left(A_{e f f}\right)\left(E_{e}\right)}
$$

where $I_{p h}=I_{\text {light }}-I_{\text {dark }}, \mathrm{A}_{\text {eff }}$ is the effective UV photodetector area, and $E_{e}$ is the optical irradiance (in $\mathrm{W} / \mathrm{m}^{2}$ ), and then

$$
\begin{aligned}
R_{s, D y \mathrm{CoO}_{3}} & =\frac{(\sim 0.685-\sim 0.376) \times 10^{-3} \mathrm{~A}}{(\pi)\left(5 \times 10^{-3} \mathrm{~m}\right)^{2}\left(1000\left(\mathrm{~W} / \mathrm{m}^{2}\right)\right)} \\
& =3.93 \times 10^{-3} \mathrm{~A} / \mathrm{W}
\end{aligned}
$$

where $I_{\text {light }}$ and $I_{\text {dark }}$ were obtained experimentally from the graph shown in Figure 9.

Comparing the resulting $\mathrm{R}_{\mathrm{s}}$ obtained in this work with those reported in the literature for other oxides used in this application: $\left(\mathrm{In}_{\mathrm{x}} \mathrm{Ga}_{1-\mathrm{x}}\right)_{2} \mathrm{O}_{3}\left(\mathrm{R}_{\mathrm{s}}=6.9 \times 10^{-5} \mathrm{AW}^{-1}\right)$ and $\beta$ $\mathrm{Ga}_{2} \mathrm{O}_{3}\left(\mathrm{R}_{\mathrm{s}}=3.72 \times 10^{-4} \mathrm{AW}^{-1}\right)$, the potential use of $\mathrm{DyCoO}_{3}$ as UV photodetector material can be noticed [34,35].

3.2.3. Detection of Light of Larger Wavelengths. The detection of radiation in the visible spectrum using semiconductor materials has been investigated since time ago. In order to know the ability of $\mathrm{DyCoO}_{3}$ to detect radiation in this region, photocurrent measurements using light sources of larger wavelengths were also tested. Figures $10(a)$ and $10(\mathrm{~b})$ show $I$ vs. time graphs recorded when light of $\lambda=400$ and $449 \mathrm{~nm}$ and $\mathrm{E}_{\mathrm{e}}=90 \mathrm{~mW} / \mathrm{cm}^{2}$ were used. From these figures, the average $\Delta I$ were 0.118 and $0.107 \mathrm{~mA}$, respectively. Comparing these results with those obtained from $\mathrm{UV}$, a decrease of $\Delta I$ of approximately 1.6 and $10.8 \%$ was observed, respectively. This can be explained by a decrease on the energy of the incoming photons. The quantitative detection of these radiations was evaluated by increasing $\mathrm{E}_{\mathrm{e}}$ from 20 to $90 \mathrm{~mW} / \mathrm{cm}^{2}$; Figures $11(\mathrm{a})$ and $11(\mathrm{~b})$ display the corresponding results. The exposure to light of $\lambda=400 \mathrm{~nm}$ 


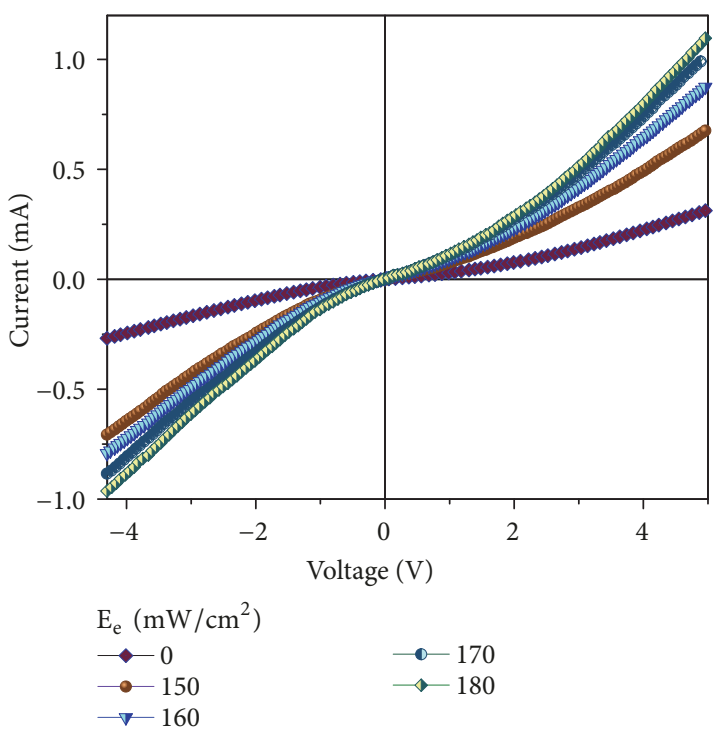

FIgURE 8: $I$-V curves recorded from $\mathrm{DyCoO}_{3}$ using UV light of several optical irradiances $\left(\mathrm{E}_{\mathrm{e}}\right)$.

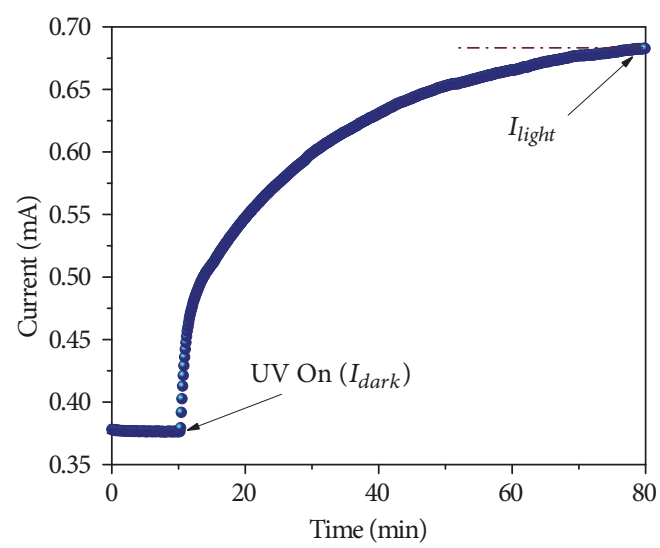

FIGURE 9: $I$ vs. $\mathrm{t}$ graph recorded with a long exposure $(60 \mathrm{~min})$ to UV light.

produced $\Delta I$ values from 0.023 to $0.075 \mathrm{~mA}$, whereas, for $\lambda=$ $449 \mathrm{~nm}, \Delta I$ varied from 0.021 to $0.069 \mathrm{~mA}$. Even though these results reveal small differences of $\Delta I$, a decrease of $\Delta I$ with $\lambda$ can be noticed. Furthermore, from Figures 11(a) and 11(b) a quasilinear relationship between $\Delta I$ and $\mathrm{E}_{\mathrm{e}}$ can be deduced, similarly to that observed for UV light.

Figure 12(a) shows a typical $I$ vs. time plot obtained when a $\operatorname{LED}$ of red light $(\lambda=642 \mathrm{~nm})$ and $\mathrm{E}_{\mathrm{e}}=90 \mathrm{~mW} / \mathrm{cm}^{2}$ was used. In this case, a significant decrease on the average $\Delta I$ was measured, being of $0.037 \mathrm{~mA}$. This value represents a decrease of $69 \%$ to that registered in UV light. Figure 12(b) displays the variation of $I$ produced by an increase on $\mathrm{E}_{\mathrm{e}}$, from 20 to $90 \mathrm{~mW} / \mathrm{cm}^{2}$. The exposure to this light produced $\Delta I$ values from 0.011 to $0.04 \mathrm{~mA}$. Besides, a quasilinear dependence of $\Delta I$ with $\mathrm{E}_{\mathrm{e}}$ can be also inferred from this graph.

The overall photocurrent results obtained from $\mathrm{DyCoO}_{3}$ revealed that photons with energy between $1.93 \mathrm{eV}$ (red) and $3.39 \mathrm{eV}$ (UV), or even higher, can be easily detected by the variation of the electrical current through the oxide. A possible application of this material can be found in photoconductive cells, which are used for saving electrical energy in artificial illumination. Some of the advantages of $\mathrm{DyCoO}_{3}$ compared to other materials used in this field are that it is easy to prepare, cost effective, and environmentally friendly. Moreover, $\mathrm{DyCoO}_{3}$ can also be applied as a detector material to monitor the UV exposure in humans, during outdoor activities.

3.3. Photocatalytic Decomposition of Malachite Green. Malachite green (MG) is a cationic triphenylmethane dye of formula $\mathrm{C}_{23} \mathrm{H}_{25} \mathrm{ClN}_{2}$, which contains three aromatic rings. It has been used in the paper, textile, leather, and fishing industries: in the latter like fungicide and antiseptic [36]. It is highly resistant to biodegradation and recently its use has been banned because of its mutagenic and cytotoxic capabilities [37]. Regarding the photocatalytic degradation of MG investigated in this work, Figure 13(a) shows the absorbance spectra obtained when $10 \mathrm{mg}$ of $\mathrm{DyCoO}_{3}$ (as powder) and UV light $\left(\mathrm{E}_{\mathrm{e}}=100 \mathrm{~mW} / \mathrm{cm}^{2}\right)$ were used. A gradual decrease of the absorbance intensity with exposure time can be noticed, indicating the degradation of MG.

Since the amount of photocatalyst used in these tests plays an important role, experiments using $20 \mathrm{mg}$ of the perovskite were also done. Figure 13(b) displays the degradation percentage obtained when 10 and $20 \mathrm{mg}$ of the perovskite were used. In this graph, the main band of MG, centered at $617 \mathrm{~nm}$, was used as reference. The results show that the degradation of the dye increased from 1.3 to $20 \%$ during the first 10 minutes, while after $2 \mathrm{~h}$ it increased from 10.8 to $47 \%$. This improvement is attributed to the increase on the surface area of $\mathrm{DyCoO}_{3}$ in contact with MG.

The correlation of the photocurrent results with the photocatalytic degradation of MG may be described in the following terms: under UV light the valence band (VB) electrons of $\mathrm{DyCoO}_{3}$ are excited to the conduction band (CB), increasing the number of holes in the VB. VB holes react with water contained in the $\mathrm{MG}$ solution producing hydroxyl radicals $\left(\mathrm{OH}^{\bullet}\right)$, according to Eq. No. (8).

$$
\mathrm{H}_{2} \mathrm{O}+h_{V B}^{+} \longrightarrow \mathrm{OH}^{\bullet}+\mathrm{H}^{+}
$$

Hydroxyl radicals are highly reactive and promote chemical reactions in short periods of time [38]. These radicals catalyze the degradation of the dye through their interaction with electron-rich sites of the MG molecules [36]. On the other hand, cobalt oxides with spinel or perovskite-type structures have good photocatalytic properties towards water oxidation [39]. The trivalent state of cobalt $\left(\mathrm{Co}^{3+}\right)$ with intermediate spin state $t_{2 g}^{5} e_{g}^{1}$ is a key factor [15]. According to the authors of that work, the presence of a single electron in the $\mathrm{e}_{\mathrm{g}}{ }^{1}$ orbital and the energy of the incoming UV photons provide the basis for oxygen evolution. Moreover, Solís et al. concluded that the charge carriers involved in the photocatalysis regenerate the original oxidation state of 


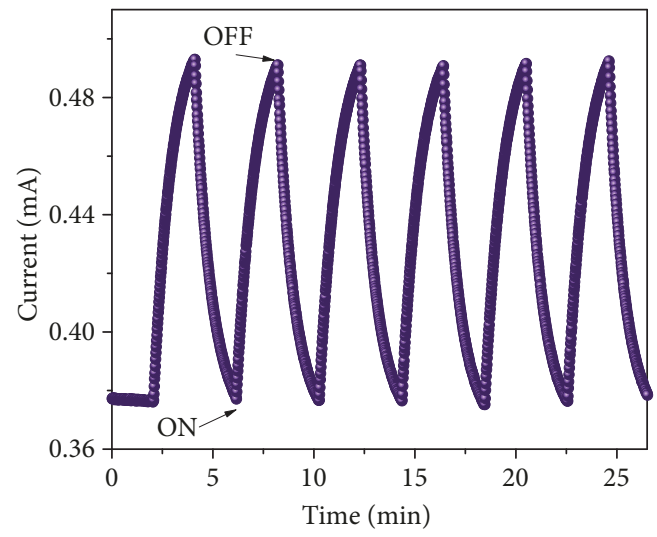

(a)

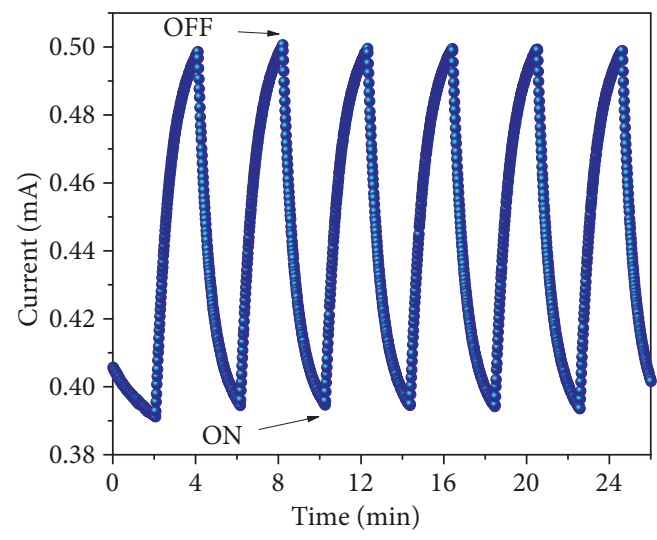

(b)

Figure 10: Photocurrent $v s$. time graphs obtained for light of $\lambda$ : (a) 400 and (b) $449 \mathrm{~nm}\left(\mathrm{E}_{\mathrm{e}}=90 \mathrm{~mW} / \mathrm{cm}^{2}\right)$.

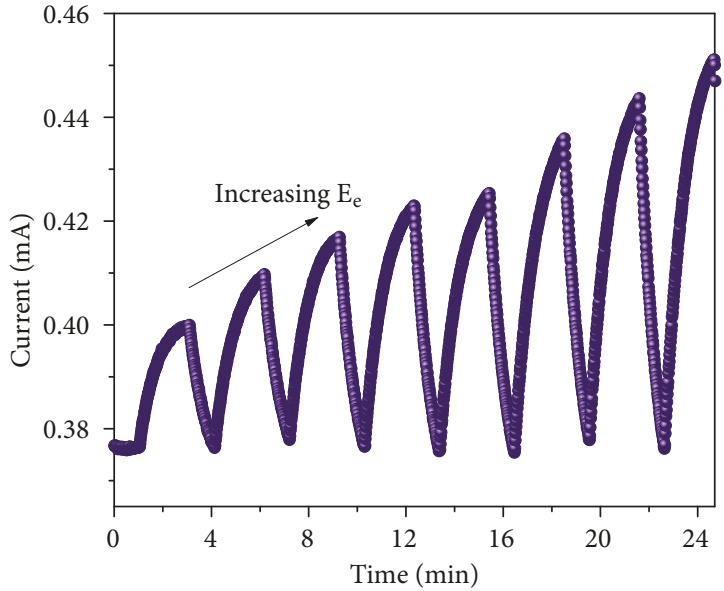

(a)

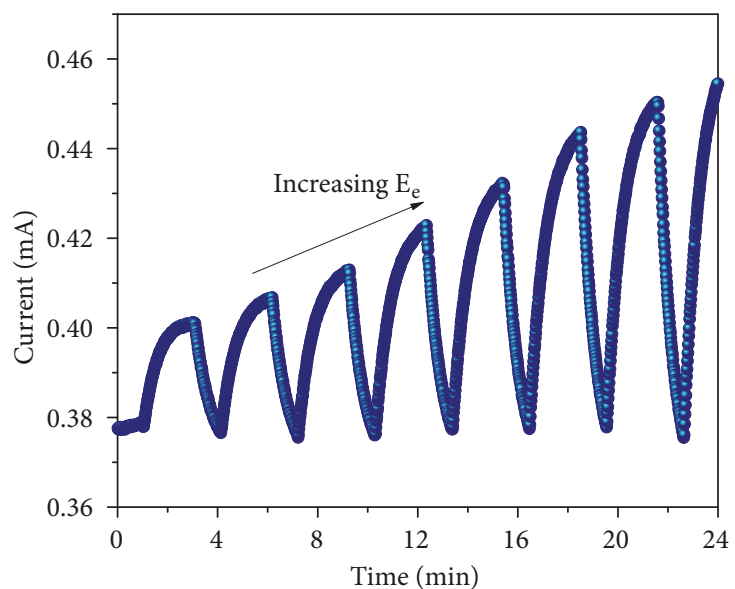

(b)

FIGURE 11: Quantitative detection of light of $\lambda:(a)=400 \mathrm{~nm}$ and (b) $449 \mathrm{~nm}$.

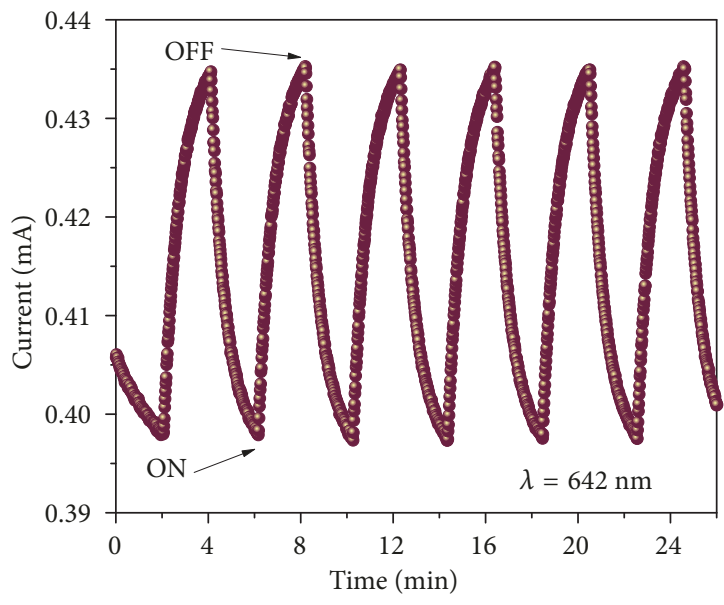

(a)

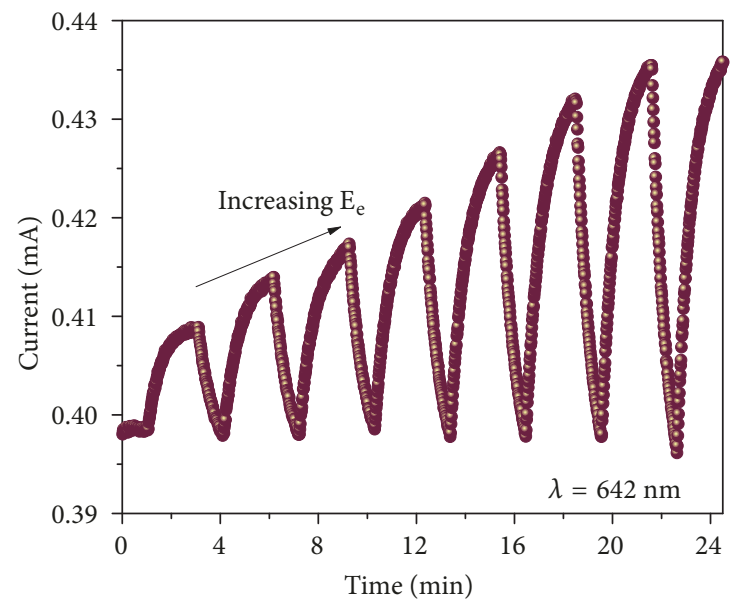

(b)

FIGURE 12: (a) $I$ vs. t graph recorded using a LED of red light $\left(\mathrm{E}_{\mathrm{e}}=90 \mathrm{~mW} / \mathrm{cm}^{2}\right)$ in on/off periods of $2 \mathrm{~min}$. (b) Variation of $I$ measured while increasing $\mathrm{E}_{\mathrm{e}}$. 


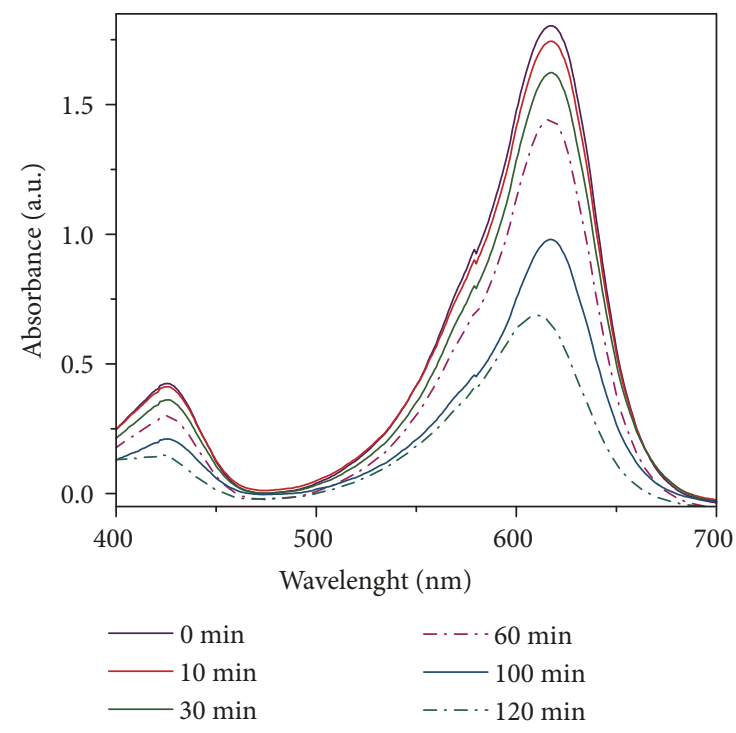

(a)

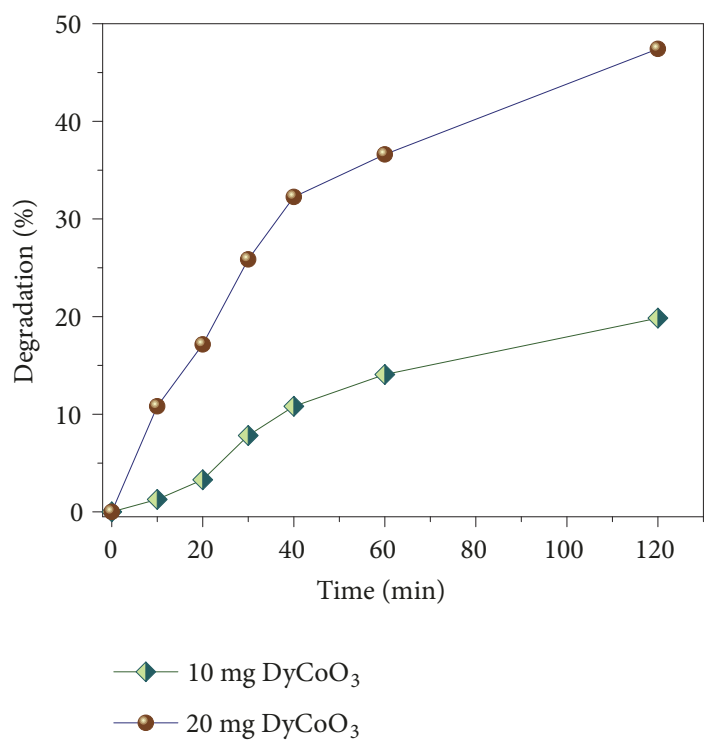

(b)

FIGURE 13: (a) UV-Vis absorption spectra corresponding to the photocatalytic decomposition of malachite green under UV light. (b) Degradation percent recorded in 10 and $20 \mathrm{mg}$ of $\mathrm{DyCoO}_{3}$.

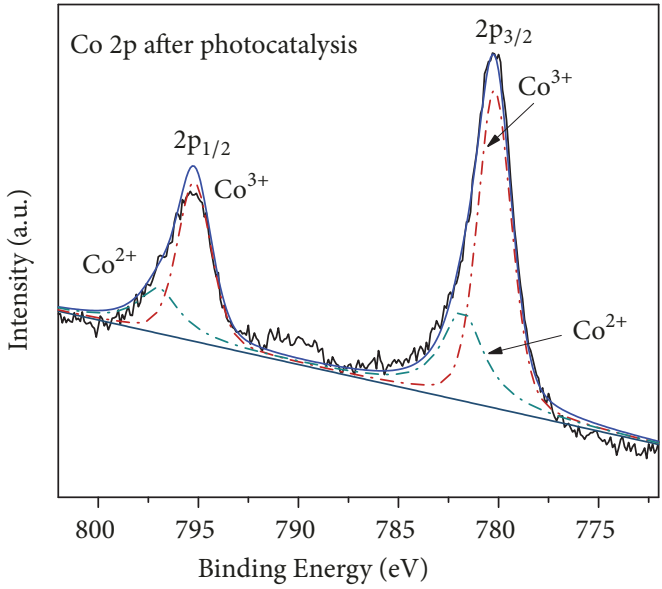

(a)

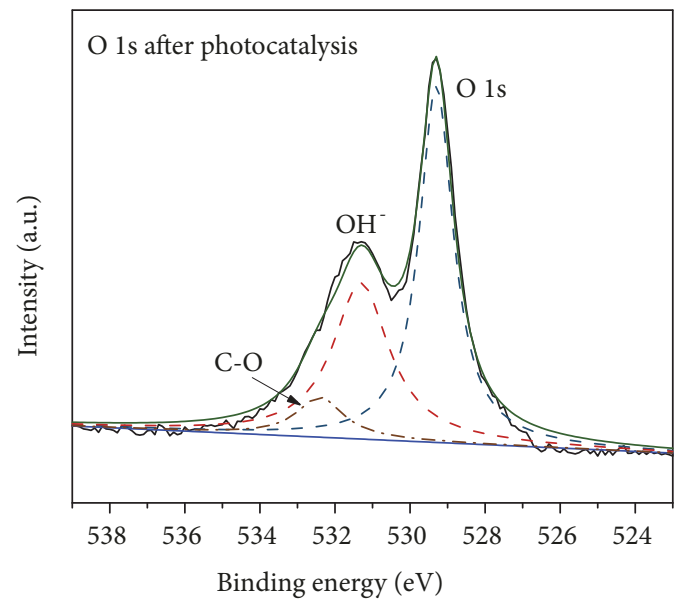

(b)

FIgURE 14: XPS narrow scans of (a) Co 2p and (b) O 1s of a $\mathrm{DyCoO}_{3}$ sample used in the photocatalytic degradation of MG.

cobalt, minimizing electron-hole recombination [40]. The latter can be written by means of Eqs. Nos. (9) and (10):

$$
\begin{aligned}
& \mathrm{Co}^{3+}+e_{\mathrm{CB}}^{-} \longrightarrow \mathrm{Co}^{2+} \\
& \mathrm{Co}^{2+}+h_{V B}^{+} \longrightarrow \mathrm{Co}^{3+}
\end{aligned}
$$

In this work, in order to find evidence of this mechanism, a sample of $\mathrm{DyCoO}_{3}$ retrieved after the UV photocatalytic degradation of MG was evaluated by XPS. Figure 14 shows narrow scan profiles registered for (a) Co $2 \mathrm{p}$ and (b) $\mathrm{O} 1 \mathrm{~s}$ levels. From Figure 14(a), the analysis of the deconvolution of the $2 \mathrm{p}_{1 / 2}$ and $2 \mathrm{p}_{3 / 2}$ levels of cobalt allowed to calculate areas of $68.34 \%$ and $31.66 \%$, for $\mathrm{Co}^{3+}$ and $\mathrm{Co}^{2+}$, respectively. Comparing these results with those obtained before the photocatalysis, the area (abundance) corresponding to $\mathrm{Co}^{3+}$ increased approximately $25 \%$, involving a decrease of the same percentage for $\mathrm{Co}^{2+}$. About the analysis of oxygen, Figure 14(b) shows an increase of $8 \%$ on the area associated to the formation of $\mathrm{OH}^{-}$ions (peak located at $531.3 \mathrm{eV}$ ), produced during the photocatalytic degradation of MG. The increase on the amount of $\mathrm{Co}^{3+}$ and $\mathrm{OH}^{-}$detected on samples used in photocatalysis supports the mechanism proposed before. However, the identification of other oxygen species like $\mathrm{O}_{2}{ }^{2-}, \mathrm{O}_{2}{ }^{-}$, and $\mathrm{O}^{-}$was not possible through XPS [41, 42]. Furthermore, the increase on the area of the peak centered at $532.4 \mathrm{eV}$ of Figure 14(b) (related to the C-O bond) can be attributed to adsorbed moiety produced during the degradation of MG. 


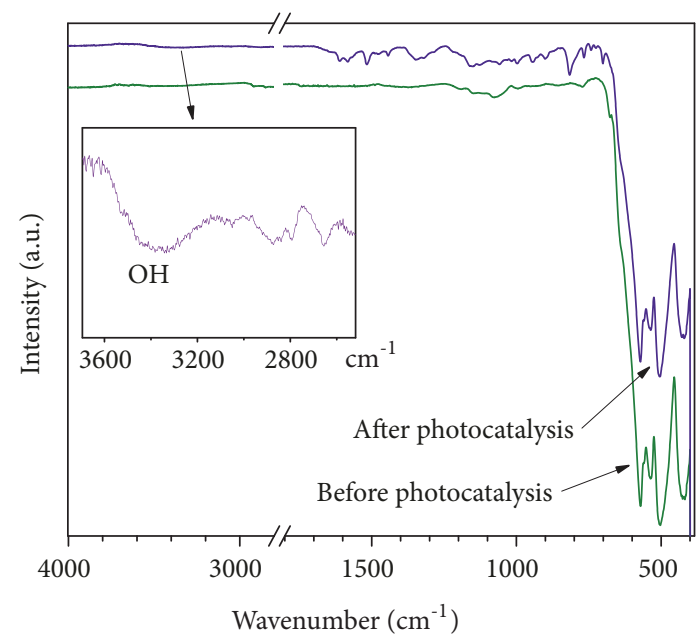

Figure 15: FTIR graphs recorded on $\mathrm{DyCoO}_{3}$ samples before and after the photocatalytic degradation of MG.

Figure 15 shows FTIR spectra of $\mathrm{DyCoO}_{3}$ before and after the photocatalytic decomposition of MG. Three strong peaks in the region $421-570 \mathrm{~cm}^{-1}$ are assigned to stretching and vibration of Co-O and Dy-O-Co bonds. The peak at $1082 \mathrm{~cm}^{-1}$, which is more evident before the photocatalysis, can be attributed to the stretching mode of $\mathrm{CO}_{3}{ }^{2-}[43,44]$. The presence of the latter agrees with the XPS result that displays the presence of carbonate (Figure 5(d)). Furthermore, after photocatalysis, new peaks appear in the FTIR spectrum. It draws attention the presence of a wide peak at $3514 \mathrm{~cm}^{-1}$, which is due to the $\mathrm{O}-\mathrm{H}$ stretching vibration. This wide band (inset of Figure 15) could be a contribution from $\mathrm{O}-\mathrm{H}$ groups in both the organic matter and the photocatalyst. In the literature, the shoulder detected at $3541 \mathrm{~cm}^{-1}$ has been associated to hydroxyl groups, bonded to lanthanides and transition metal oxide cations [45]. Therefore, this signal can be assigned to $\mathrm{OH}^{-}$generated on the surface of the $\mathrm{DyCoO}_{3}$ photocatalyst. The peaks observed after photocatalysis in the region $1700-700 \mathrm{~cm}^{-1}$ are related to moiety containing $\mathrm{C}=\mathrm{C}$ (aromatic rings), $\mathrm{C}=\mathrm{O}, \mathrm{C}-\mathrm{H}$, and $\mathrm{C}-\mathrm{N}$ groups of the dye. However, the $\mathrm{O}_{2}{ }^{-}$radical could not be identified by this technique, possibly due to its short life. In summary, FTIR results supported the mechanism of degradation based on the formation of $\mathrm{OH}^{-}$radicals by UV radiation. These radicals break the dye molecules and the resulting fragments (moiety) have been associated to peaks observed by XPS and FTIR.

3.4. Conclusions. $\mathrm{DyCoO}_{3}$ displays a unique crystal structure with outstanding magnetic and electrical properties. However, other interesting properties, such as photoconductivity and photocatalytic activity, have not been published before, in our knowledge. Therefore, in this work $\mathrm{DyCoO}_{3}$ was prepared by a straightforward wet chemistry method, using PVA as a polymerizing agent. Compared to other approaches, it was obtained at a lower calcination temperature and its microstructure displays an extensive network of micron sized grains and abundant porosity. The photocurrent results obtained from pellets of $\mathrm{DyCoO}_{3}$ revealed a reproducible detection of light in the UV and visible regions. These results suggest its possible application in photoconductive cells for saving electric energy and UV detectors for preventing skin cancer, among others. On the other hand, compared to other semiconductor materials the photocatalytic activity of $\mathrm{DyCoO}_{3}$ toward the decomposition of MG revealed a moderate performance. However, it can be improved through the optimization of the synthesis method, with the purpose of producing nanostructured particles.

\section{Data Availability}

The data used to support the findings of this study are available from the corresponding author upon request.

\section{Conflicts of Interest}

The authors declare that they have no conflicts of interest about the publication of this work.

\section{Acknowledgments}

The authors are grateful to Coordinación General Académica of Universidad de Guadalajara for financial support through PRO-SNI 2018 program. M. A. Lopez-Alvarez thanks CONACYT for his Ph.D. scholarship in the CUCEI, Universidad de Guadalajara.

\section{References}

[1] M. A. Peña and J. L. G. Fierro, "Chemical structures and performance of perovskite oxides," Chemical Reviews, vol. 101, no. 7, pp. 1981-2018, 2001.

[2] K.-Y. A. Lin, Y.-C. Chen, and Y.-F. Lin, "LaMO3 perovskites $(\mathrm{M}=\mathrm{Co}, \mathrm{Cu}, \mathrm{Fe}$ and $\mathrm{Ni}$ ) as heterogeneous catalysts for activating peroxymonosulfate in water," Chemical Engineering Science, vol. 160, pp. 96-105, 2017.

[3] H. Zhu, P. Zhang, and S. Dai, "Recent advances of lanthanumbased perovskite oxides for catalysis," ACS Catalysis, vol. 5, no. 11, pp. 6370-6385, 2015.

[4] O. Parkash, P. Ganguly, G. R. Rao, C. N. R. Rao, D. S. Rajoria, and V. G. Bhide, "Rare earth cobaltite catalysts: relation of activity to spin and valence states of cobalt," Materials Research Bulletin, vol. 9, no. 9, pp. 1173-1176, 1974.

[5] T. Ishihara, Ed., Perovskite Oxide, for Solid Oxide Fuel Cells, Springer, Dordrecht, Netherlands, 2009.

[6] Z. Jirák, J. Hejtmánek, K. Knížek, and M. Veverka, “Electrical resistivity and thermopower measurements of the hole- and electron-doped cobaltites $\mathrm{LnCoO}_{3}$," Physical Review B: Condensed Matter and Materials Physics, vol. 78, no. 1, p. 014432, 2008.

[7] J.-C. Ding, H.-Y. Li, Z.-X. Cai, X.-D. Zhang, and X. Guo, "LaCoO3-based sensors with high sensitivity to carbon monoxide," RSC Advances, vol. 5, no. 81, pp. 65668-65673, 2015.

[8] C. R. Michel, A. H. Martínez-Preciado, E. R. López-Mena, A. Elías-Zuñiga, N. Cayetano-Castro, and O. Ceballos-Sanchez, "Improvement of the gas sensing response of nanostructured $\mathrm{LaCoO} 3$ by the addition of Ag nanoparticles," Sensors and Actuators B: Chemical, vol. 246, pp. 181-189, 2017. 
[9] P. Mahata, T. Aarthi, G. Madras, and S. Natarajan, "Photocatalytic Degradation of Dyes and Organics with Nanosized GdCoO 3," The Journal of Physical Chemistry C, vol. 111, no. 4, pp. 1665-1674, 2007.

[10] S. Fu, H. Niu, Z. Tao et al., "Low temperature synthesis and photocatalytic property of perovskite type $\mathrm{LaCoO} 3$ hollow spheres," Journal of Alloys and Compounds, vol. 576, pp. 5-12, 2013.

[11] W. Y. Jung and S.-S. Hong, "Synthesis of $\mathrm{LaCoO} 3$ nanoparticles by microwave process and their photocatalytic activity under visible light irradiation," Journal of Industrial and Engineering Chemistry, vol. 19, no. 1, pp. 157-160, 2013.

[12] G. Thornton, F. C. Morrison, S. Partington, B. C. Tofield, and D. E. Williams, "The rare-earth cobaltites: localized or collective electron behaviour?" Journal of Physics C: Solid State Physics, vol. 21, no. 15, pp. 2871-2880, 1988.

[13] J. B. Goodenough, "An interpretation of the magnetic properties of the perovskite-type mixed crystals Lal-xSrxCoO3- $\lambda$," Journal of Physics and Chemistry of Solids, vol. 6, no. 2-3, pp. 287-297, 1958.

[14] A. N. Petrov, O. F. Kononchuk, A. V. Andreev, V. A. Cherepanov, and P. Kofstad, "Crystal structure, electrical and magnetic properties of Lal - xSrxCoO3 - y," Solid State Ionics, vol. 80, no. 3-4, pp. 189-199, 1995.

[15] U. Maitra, A. Govindaraj, and C. N. R. Rao, "Importance of trivalency and the eg 1 configuration in the photocatalytic oxidation of water by $\mathrm{mn}$ and co oxides," Proceedings of the National Acadamy of Sciences of the United States of America, vol. 110, no. 29, pp. 11704-11707, 2013.

[16] B. L. Diffey, "Sources and measurement of ultraviolet radiation," Methods, vol. 28, no. 1, pp. 4-13, 2002.

[17] D. L. Narayanan, R. N. Saladi, and J. L. Fox, "Review: ultraviolet radiation and skin cancer," International Journal of Dermatology, vol. 49, no. 9, pp. 978-986, 2010.

[18] C. A. Kolb, M. A. Käser, J. Kopecký, G. Zotz, M. Riederer, and E. E. Pfündel, "Effects of natural intensities of visible and ultraviolet radiation on epidermal ultraviolet screening and photosynthesis in grape leaves," Plant Physiology, vol. 127, no. 3, pp. 863-875, 2001.

[19] S. Sharma, M. Tomar, N. K. Puri, and V. Gupta, "Ultraviolet radiation detection by barium titanate thin films grown by solgel hydrothermal method," Procedia Engineering, vol. 87, pp. 1172-1175, 2014.

[20] J. Xing, K. Zhao, H. B. Lu et al., "Visible-blind, ultravioletsensitive photodetector based on SrTiO 3 single crystal," Optics Expresss, vol. 32, no. 17, pp. 2526-2528, 2007.

[21] E. Guo, J. Xing, K. Jin, H. Lu, J. Wen, and G. Yang, "Photoelectric effects of ultraviolet fast response and high sensitivity in LiNbO3 single crystal," Journal of Applied Physics, vol. 106, no. 2, p. 023114, 2009.

[22] E. Guo, J. Xing, H. Lu, K. Jin, J. Wen, and G. Yang, “ Ultraviolet fast-response photoelectric effects in LiTaO 3 single crystal ", Journal of Physics D: Applied Physics, vol. 43, no. 1, p. 015402, 2010.

[23] H. Liu, B. Guo, K. Zheng et al., "Novel visible-light-driven photoconductive properties of $\mathrm{LaCoO} 3$ epitaxial nano-thin films," Materials Letters, vol. 209, pp. 446-449, 2017.

[24] B. Dong, Z. Li, Z. Li et al., "Highly efficient LaCoO3 nanofibers catalysts for photocatalytic degradation of rhodamine B," Journal of the American Ceramic Society, vol. 93, no. 11, pp. 35873590, 2010.
[25] J. A. Alonso, M. J. Martínez-Lope, C. de La Calle, and V. Pomjakushin, "Preparation and structural study from neutron diffraction data of $\mathrm{RCoO}_{3}(\mathrm{R}=\mathrm{Pr}, \mathrm{Tb}, \mathrm{Dy}, \mathrm{Ho}, \mathrm{Er}, \mathrm{Tm}, \mathrm{Yb}, \mathrm{Lu})$ perovskites," Journal of Materials Chemistry, vol. 16, pp. 15551560, 2006.

[26] M. G. Kim, Y. S. Im, E. J. Oh, K. H. Kim, and C. H. Yo, "The substitution effect of $\mathrm{Ca} 2+$ ion on the physical properties in nonstoichiometric Dyl-xCaxCoO3-y system," Physica B: Condensed Matter, vol. 229, no. 3-4, pp. 338-346, 1997.

[27] J. Gutiérrez Seijas, J. Prado-Gonjal, D. Ávila Brande, I. Terry, E. Morán, and R. Schmidt, "Microwave-assisted synthesis, microstructure, and magnetic properties of rare-earth cobaltites," Inorganic Chemistry, vol. 56, no. 1, pp. 627-633, 2017.

[28] J. F. Moulder, W. F. Stickle, P. E. Sobol, and K. D. Bomben, Handbook of X-Ray Photoelectron Spectroscopy, Perkin-Elmer Corp., Eden Prairie, Minn, USA, 1992.

[29] X. Dong, X. Cheng, X. Zhang et al., "A novel coral-shaped Dy2O3 gas sensor for high sensitivity $\mathrm{NH} 3$ detection at room temperature," Sensors and Actuators B: Chemical, vol. 255, pp. 1308-1315, 2018.

[30] H. Chen, K. Liu, L. Hu, A. A. Al-Ghamdi, and X. Fang, "New concept ultraviolet photodetectors," Materials Today, vol. 18, no. 9, pp. 493-502, 2015.

[31] L. Sang, M. Liao, and M. Sumiya, "A comprehensive review of semiconductor ultraviolet photodetectors: from thin film to one-dimensional nanostructures," Sensors, vol. 13, no. 8, pp. 10482-10518, 2013.

[32] K. Knížek, Z. Jirák, P. Novák, and C. De La Cruz, "Non-collinear magnetic structures of $\mathrm{TbCoO} 3$ and $\mathrm{DyCoO}$ 3," Solid State Sciences, vol. 28, pp. 26-30, 2014.

[33] W. H. Jung, "Dielectric relaxation due to small polaron in DyCoO3," Physica B: Condensed Matter, vol. 292, no. 3-4, pp. 320-322, 2000.

[34] T.-H. Chang, S.-J. Chang, W.-Y. Weng, C.-J. Chiu, and C.-Y. Wei, "Amorphous Indium-Gallium-Oxide UV Photodetectors," IEEE Photonics Technology Letters, vol. 27, no. 19, pp. 2083-2086, 2015.

[35] W. Y. Weng, T. J. Hsueh, S.-J. Chang, G. J. Huang, and S. C. Hung, "Growth of $\mathrm{Ga} 2 \mathrm{O} 3$ nanowires and the fabrication of solar-blind photodetector," IEEE Transactions on Nanotechnology, vol. 10, no. 5, pp. 1047-1052, 2011.

[36] L. A. Pérez-Estrada, A. Agüera, M. D. Hernando, S. Malato, and A. R. Fernández-Alba, "Photodegradation of malachite green under natural sunlight irradiation: Kinetic and toxicity of the transformation products," Chemosphere, vol. 70, no. 11, pp. 2068-2075, 2008.

[37] L. Yong, G. Zhanqi, J. Yuefei et al., "Photodegradation of malachite green under simulated and natural irradiation: Kinetics, products, and pathways," Journal of Hazardous Materials, vol. 285, pp. 127-136, 2015.

[38] Y. Nosaka and A. Y. Nosaka, "Generation and Detection of Reactive Oxygen Species in Photocatalysis," Chemical Reviews, vol. 117, no. 17, pp. 11302-11336, 2017.

[39] B. S. Naidu, U. Gupta, U. Maitra, and C. N. R. Rao, "Visible light induced oxidation of water by rare earth manganites, cobaltites and related oxides," Chemical Physics Letters, vol. 591, pp. 277281, 2014.

[40] R. R. Solís, F. J. Rivas, O. Gimeno, and J.-L. Pérez-Bote, "Synergism between peroxymonosulfate and $\mathrm{LaCoO} 3-\mathrm{TiO} 2$ photocatalysis for oxidation of herbicides. Operational variables and catalyst characterization assessment," Journal of Chemical Technology and Biotechnology, vol. 92, no. 8, pp. 2159-2170, 2017. 
[41] N. A. Merino, B. P. Barbero, P. Eloy, and L. E. Cadús, " $\mathrm{La}_{1-x} \mathrm{Ca}_{x} \mathrm{CoO}_{3}$ perovskite-type oxides: identification of the surface oxygen species by XPS," Applied Surface Science, vol. 253, no. 3, pp. 1489-1493, 2006.

[42] T. Tian, M. Zhan, W. Wang, and C. Chen, "Surface properties and catalytic performance in methane combustion of La0.7Sr0.3Fel-yGayO3- $\delta$ perovskite-type oxides," Catalysis Communications, vol. 10, no. 5, pp. 513-517, 2009.

[43] M. Salavati-Niasari, J. Javidi, and F. Davar, "Sonochemical synthesis of Dy2(CO3)3 nanoparticles, $\mathrm{Dy}(\mathrm{OH}) 3$ nanotubes and their conversion to Dy2O3 nanoparticles," Ultrasonics Sonochemistry, vol. 17, no. 5, pp. 870-877, 2010.

[44] W. F. Edgell, C. Magee, and G. Gallup, “The Infrared Spectrum of Cobalt Carbonyl Hydride," Journal of the American Chemical Society, vol. 78, no. 17, pp. 4185-4188, 1956.

[45] A. C. T. Cursino, V. Rives, G. G. C. Arizaga, R. Trujillano, and F. Wypych, "Rare earth and zinc layered hydroxide salts intercalated with the 2-aminobenzoate anion as organic luminescent sensitizer," Materials Research Bulletin, vol. 70, pp. 336-342, 2015. 


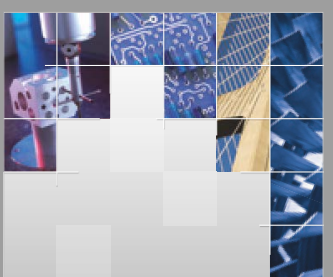

\section{Enfincering}
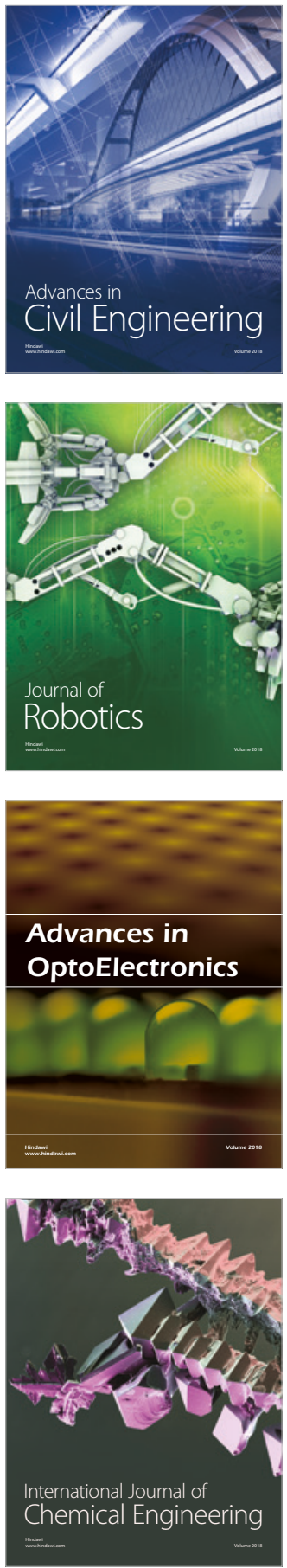

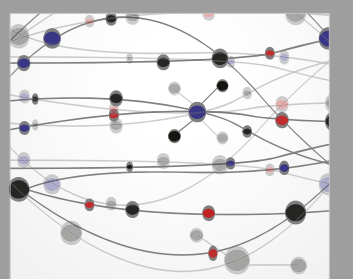

\section{Rotating \\ Machinery}

The Scientific World Journal

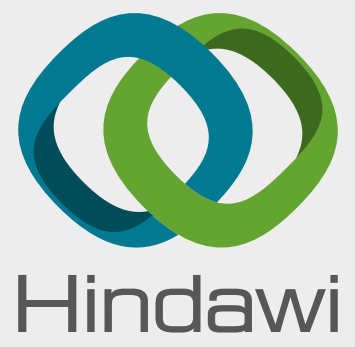

Submit your manuscripts at

www.hindawi.com
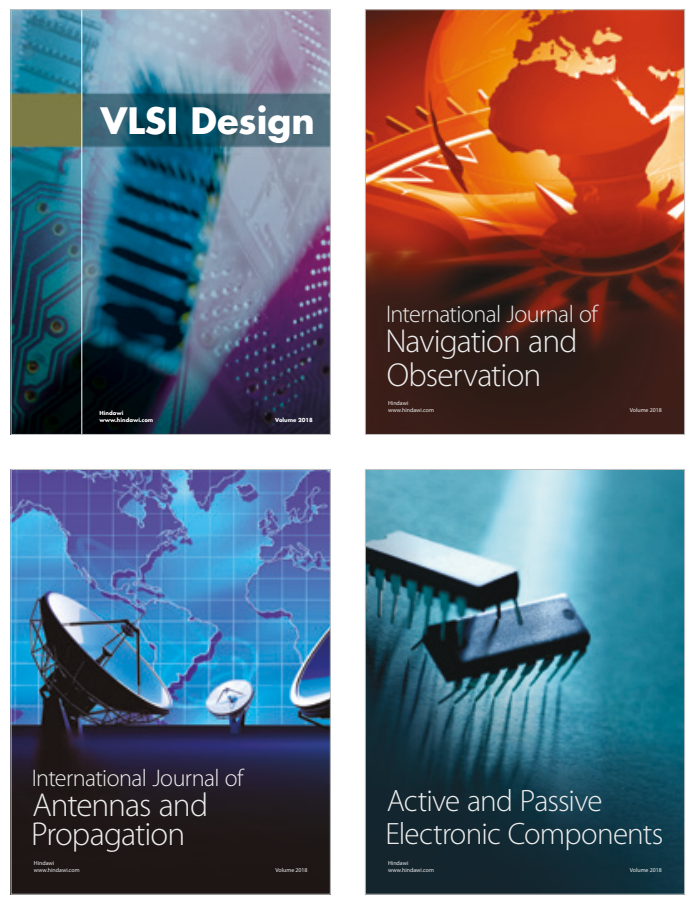
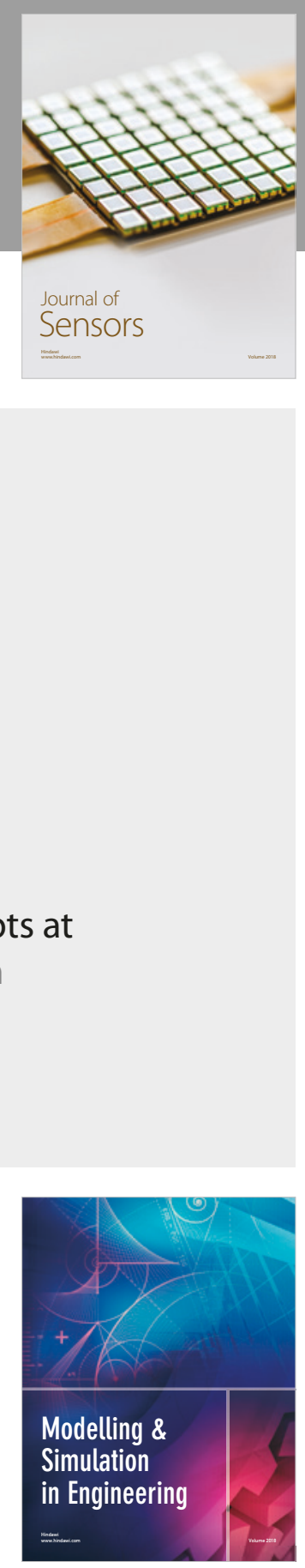

\section{Advances \\ Multimedia}
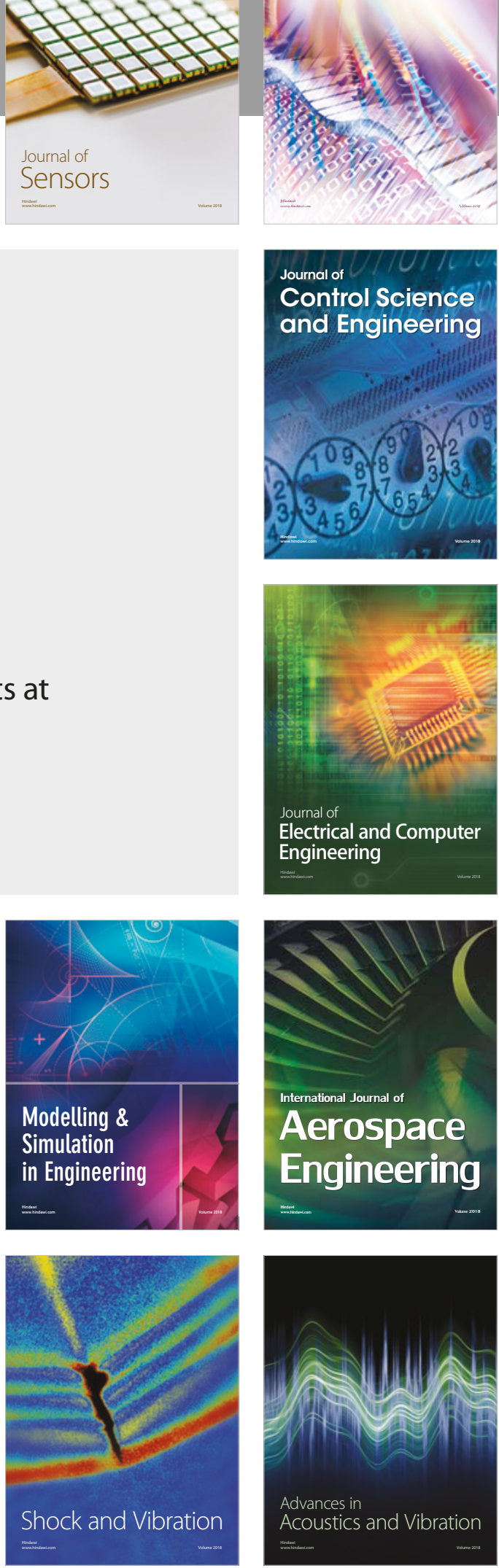